\title{
Específico e Indeterminado: A arquitetura de Grandjean de Montigny e a Casa França-Brasil
}

\author{
Thiago de Almeida \\ Mestre pelo PROURB-UFRJ. \\ Contato: ta@agenciatpba.com
}

\section{RESUMO}

Um ano antes de vir ao Rio de Janeiro, para a conclusão de seus estudos feitos na Itália no decorrer do Prix de Rome, Grandjean de Montigny publicou, em 1815, o livro Architecture Toscane com uma coleção de edifícios do Renascimento italiano de arquitetos como Brunelleschi e Alberti. De modo consciente, Montigny estudou sua coleção de exemplares arquitetônicos a fim de compreender o potencial de produzir, com base neles, novos projetos. Em 2021, um ano após celebrar o s eu segundo centenário, a Casa França-Brasil de Montigny continua a representar um protótipo espacial único que nos permite analisar a importância que sua teoria de projeto pode ter para a prática contemporânea.

Palavras-chave: Arquitetura; Grandjean de Montigny; Casa França-Brasil.

\section{Specific and Indeterminate: The Architecture of Grandjean de Montigny and the Casa França-Brasil}

\begin{abstract}
A year before coming to Rio de Janeiro, as part of the conclusion of his studies in Italy, during the Prix de Rome, Grandjean de Montigny published, in 1815, the book Architecture Toscane with a collection of Italian Renaissance buildings by architects such as Brunelleschi and Alberti. Montigny consciously studied this collection of architectural prototypes in order to understand the potential of producing new projects based on them. In 2021, a year after celebrating its second centenary, the Casa França-Brasil, designed by Montigny, continues to represent a unique spatial prototype that allows us to analyze the importance that his design theory can have for contemporary practice.
\end{abstract}

Keywords: Architecture; Grandjean de Montigny; Casa França-Brasil. 
No texto Arquitetura para Museus ([1968] 1977), escrito dois anos após a publicação do famoso livro Arquitetura da Cidade, Aldo Rossi disserta sobre a importância das teorias de projeto - ou explicações racionais do fazer arquitetônico. Após utilizar uma declaração de Adolf Loos para descrever sua ideia da "boa arquitetura", ${ }^{1}$ a qual acredito ter sido a mais bela que já li, Rossi baseia a conclusão do texto em uma declaração do pintor francês Paul Cézanne: "pinto apenas para museus" (apud ROSSI, [1968] 1977, p. 209, tradução do autor). Ao estabelecer tal condição a priori, Cézanne relativizou qualquer futura circunstância real de uma encomenda. Cada trabalho seria pré-contextualizado intencionalmente, antes mesmo de concebido, em um campo cultural autônomo formado por um universo próprio de ideias. Trata-se de um referencial teórico pelo qual ele almejava que seus trabalhos fossem interpretados a partir da relação com uma seleção específica de obras de relevância histórica. Esse seria o único contexto no qual, para Cézanne, sua arte poderia ser compreendida integralmente.

A ideia que a arquitetura, para além da importante relação direta com seu contexto real de inserção, precisa ser entendida enquanto manifestação cultural parece ser o ponto que interessa a Rossi. Tal abordagem deveria se relacionar primeiro com questões intrínsecas à arquitetura para, depois, por meio dela, lidar com a cidade. ${ }^{2}$

Em Arquitetura para Museus, o arquiteto italiano formula sua teoria de projeto - não exatamente no projeto de museus, como o título parece sugerir - no argumento que uma arquitetura também só pode ser plenamente avaliada e compreendida a partir da relação com o universo específico de ideias e premissas que baseou sua concepção. Nesse sentido, uma arquitetura deveria poder ser descrita pela analogia com outras arquiteturas como modo de comunicar seus significados e intenções.

Rossi exalta a arquitetura como técnica, enquanto conhecimento coletivo baseado em princípios essenciais transmitidos entre gerações. Na citação do filósofo romano Seneca — "é o tolo, que, ao começar, sempre retorna ao início e que se recusa a seguir, de maneira contínua, o caminho de sua própria experiência" (apud ROSSI, [1968] 1977, p. 202, tradução do autor) - , está a defesa por uma produção arquitetônica desenvolvida de modo coerente por intermédio de um saber acumulado e de possível descrição através do seu referencial teórico. Como exemplos, menciona os estudos feitos por Le Corbusier e Adolf Loos sobre a arquitetura da
Antiguidade no início do século XX, que serviram de base para o modernismo, e também os arquitetos neoclassicistas franceses que foram à Itália entre os séculos XVIII e XIX, em virtude do Prix de Rome. Nesse caso, a intenção era estudar exemplares da arquitetura greco-romana e renascentista que serviriam como base para a concepção dos edifícios que representariam os ideais da nova França Revolucionária.

Entre os arquitetos revolucionários franceses ganhadores do Prix de Rome, está Grandjean de Montigny, reconhecido como um dos principais integrantes da Missão Artística Francesa $^{3}$ (RIOS FILHO, 1941, p. 291), vinda ao Brasil em 1816, e como o responsável pelo início da renovação da arquitetura brasileira (COSTA, 1995, p. 157). Na busca por um novo objetivo para sua arquitetura após a dissolução do Império Napoleônico, Montigny aceitou, junto com um grupo de notáveis artistas franceses, como Debret e Pradier, o convite de Portugal para participar da fundação de uma escola de ensino em artes visuais no Rio de Janeiro. Assim, teria a oportunidade de contribuir com a transformação cultural da simples cidade colonial na nova capital do reino português. Enquanto aguardava a inauguração da escola que, por razões políticas, só aconteceria em 1825, recebeu diversas encomendas para realizar intervenções efêmeras na arquitetura da cidade, como pavilhões, arenas e cenários de festividades. Em 1819, foi convidado a projetar o edifício da Praça do Comércio (atual Casa França-Brasil). Cercado de grandes expectativas, o edifício-praça, inaugurado rapidamente no ano seguinte, é hoje um dos mais importantes exemplares da arquitetura neoclássica de Montigny.

Um ano antes de vir ao Rio de Janeiro, para a conclusão de seus estudos feitos na Itália no decorrer do Prix de Rome, Montigny publicou, em 1815, o livro Architecture Toscane (MONTIGNY e FAMIN, 1815) com uma coleção de edifícios do Renascimento italiano projetados por arquitetos como Alberti, Brunelleschi, Palladio e Scamozzi. É possível analisar a investigação formal encontrada no livro - e todos os desenhos e textos produzidos de modo a coletá-la - como a convergência de uma intenção arquitetônica específica. Conforme seus mestres franceses Percier e Fontaine, que haviam publicado, em 1798, um livro sobre arquitetura romana, e Étienne-Louis Boullée, com a publicação, em 1795, de sua coleção de tipos de casas, a intenção de Montigny era colaborar com a expansão de um vocabulário arquitetônico coletivo que seria utilizado como referência na construção da nova França revolucionária.

Revista online do Departamento de Arquitetura e Urbanismo da 
Para esses arquitetos, a boa arquitetura de ordem pública, que representaria os valores da revolução social em curso na França, deveria recuperar as premissas da arquitetura clássica de modo a alcançar a mesma monumentalidade nobre, simples e precisa. Existia, entre os arquitetos neoclássicos franceses, a crença no poder da arquitetura em influenciar o modo de pensar e os valores de uma sociedade. Significava, portanto, trabalhar com os meios disponíveis de maneira econômica e essencial, oposta aos excessos de ordem estética na afirmação de um status quo exclusivo e superior antes vistos em construções ligadas à monarquia e à Igreja.

Produzir um livro a partir da seleção de protótipos era a maneira de tornar a história operacional visando a realização de uma arquitetura hipotética. A representação gráfica do livro, com destaque para as particularidades construtivas e para o espaço interior dos exemplares selecionados, além da quase total ausência de descrição sobre funções e contexto urbano de inserção, são sugestivas dessa intenção. Segundo Angela Telles, no seu livro sobre a obra do arquiteto francês, estava claro para Montigny que as arquiteturas de sua coleção eram "tipos que possibilitavam significações infinitas” (TELLES, 2008, p. 148).

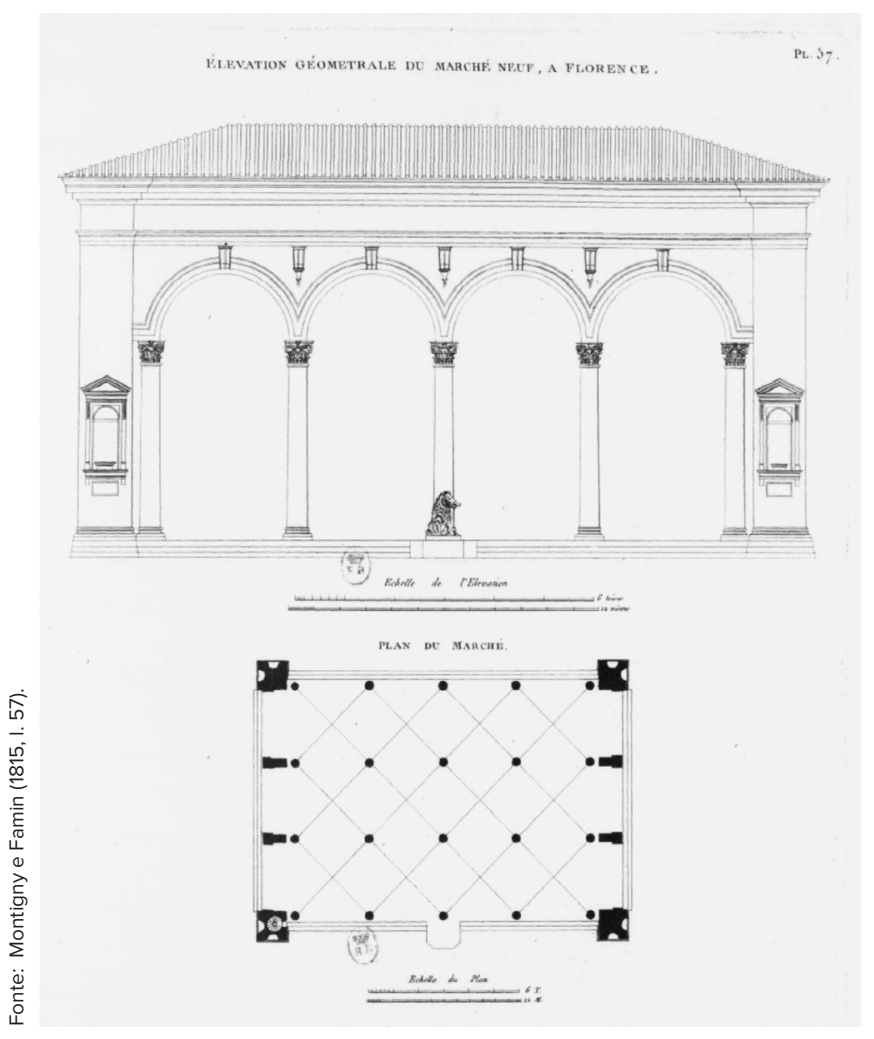

Figura 1. Planta baixa e elevação do Mercado Novo de Florença.

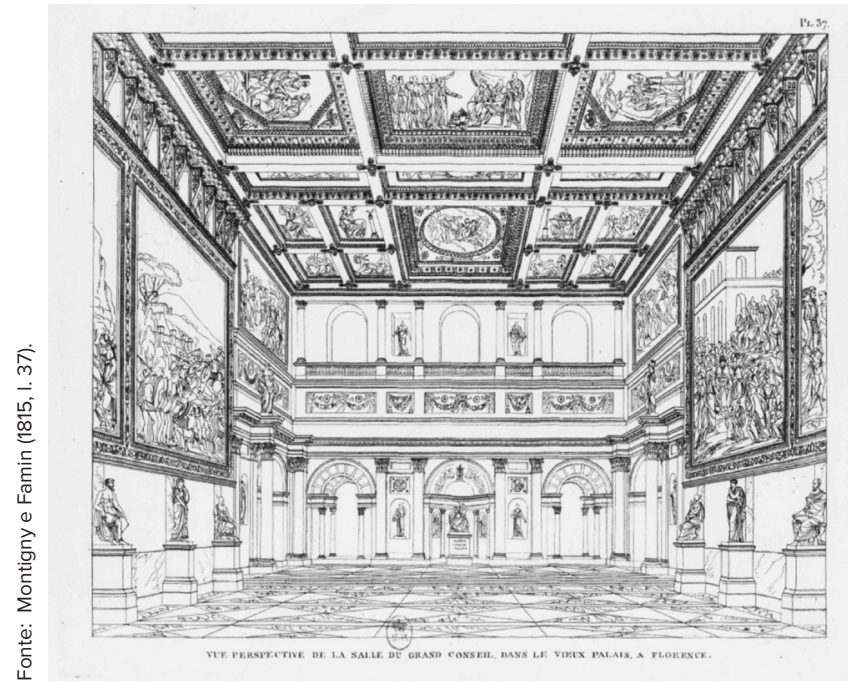

Figura 2. Perspectiva interior da Sala do Grande Conselho no Palácio Velho de Florença.

Ao projetar por meio de uma coleção, Montigny poderia, conforme Cézanne, pré-contextualizar sua prática de modo a torná-la coerente dentro de um campo cultural autônomo. Em um possível paralelo com o conceito de "autonomia da arquitetura” ${ }^{4}$ defendido por Rossi, a concepção de um novo espaço era viável, para Montigny, através de visões anteriores daquele mesmo espaço construído em outras formas e circunstâncias como garantia de alcance de uma qualidade específica já conhecida. Entretanto, tal conceito aponta também para uma autonomia teórica e parcial, limitada no momento de confronto com a realidade. Sendo assim, todo novo projeto seria a encarnação da mesma ideia de arquitetura, concebida, cada vez, de maneira diferente de acordo com as condicionantes de seu contexto de inserção. A especificidade da arquitetura de Montigny residiria no modo como tais referências históricas seriam apropriadas e combinadas em novas soluções. Nesse processo, um caráter construtivo específico seria desenvolvido pela reprodução de certas qualidades identificadas como clássicas e universalmente inteligíveis, sejam elas de ordem formal, tectônica ou estética.

De modo consciente, Montigny estudou e catalogou sua coleção de exemplares arquitetônicos a fim de compreender o potencial de produzir, com base neles, novos projetos. Essa abordagem encontra um segundo paralelo na teoria de Rossi dentro do conceito de "tipo", ${ }_{5}^{5}$ modo de categorizar grupos de edifícios não por suas funções, mas pelas características formais e espaciais que compartilham entre si. No livro sobre a arquitetura toscana, a predominância de ilustrações dos pátios, galerias e salões encontrados nos palácios, igrejas e

Revista online do Departamento de Arquitetura e Urbanismo da Pontifícia Universidade Católica do Rio de Janeiro - PUC-Rio, Brasil Ano 8 - No으 9 - ISSN 2446-7340 
equipamentos urbanos de Florença parece indicar um interesse primeiramente espacial de Montigny. Em principal, são tipos espaciais generosos que reúnem qualidades que os tornam aptos a abrigar diversos usos e funções. A partir desse caráter funcional indeterminado, seriam exemplares ideais na composição de um catálogo de protótipos universais para os edifícios públicos da nova França Revolucionária. Ainda de acordo com Rossi, é fundamental o entendimento da cidade como uma construção coletiva que acontece no longue durée,$^{6}$ tempo expandido onde transformações espaciais são geradas no decorrer do lento desenvolvimento de novos significados de ordem social e de sua influência no meio urbano. Nessa condição, também é possível o entendimento da indeterminação espacial como qualidade estratégica para uma arquitetura ser funcionalmente ambígua e assim se manter aberta a novas significações na esperança de continuar relevante no decorrer de sua existência.

Sendo um dos principais representantes da missão cultural encomendada por Portugal, o arquiteto francês encontrou no Rio de Janeiro uma segunda oportunidade para utilizar o seu repertório de protótipos espaciais. Entre os diversos projetos de edifícios públicos produzidos por ele, estão, além da Praça do Comércio (Casa França-Brasil) (1819-20), a Academia Imperial de Belas Artes (1816-26, demolido), a Praça Monumental do Campo de Santana (1827, não construído), a Catedral de São Pedro de Alcântara (1827, não construído), o Edifício do Mercado (1834, demolido), o Chafariz da Carioca (1838, demolido), a Biblioteca Imperial (1842, não construído), o Paço do Senado (1848, não construído) e o Palácio Imperial (1848, não construído), entre muitos outros edifícios privados, infelizmente em grande parte também demolidos.

Nesse contexto, torna-se interessante analisar a Casa França-Brasil, único edifício público projetado por Montigny ainda existente. ${ }^{7}$ Enquanto primeira arquitetura a ser construída pela Missão Francesa, precisava corresponder às expectativas por um edifício magnífico como representação da nova cultura que marcaria a transição da cidade colonial para capital do Reino de Portugal. De acordo com a tipologia de edifício-praça, era almejado um grande recinto urbano coberto contíguo ao tecido da cidade, disponível para eventos públicos e para reunião de homens de negócios. As ambições estéticas e de escala contrastavam, como de costume ainda hoje, diretamente com as circunstâncias presentes na encomenda do edifício e em sua construção. No entanto, o precipitado cronograma de execução em apenas um ano e o orçamento limitado parecem ter servido para ressaltar o in- teresse de Montigny - destacado no livro Architecture Tosca$n e$ - pela arquitetura baseada em uma economia de meios como maneira de negociar com o mundo real sua existência. "Quanto mais aumentamos a massa, menos devemos multiplicar os detalhes" (MONTIGNY e FAMIN, 1815, p. vj, tradução do autor). Na construção das fachadas, os poucos ornamentos existentes no projeto original foram suprimidos e suas ausências acentuam ainda mais a sobriedade da arquitetura. É possível imaginar que, diante da necessidade em fazer escolhas, essa patente indiferença em relação à simplicidade externa do edifício tenha possibilitado a Montigny concentrar esforços na concretização da nobre monumentalidade do espaço interior como atributo formador da expressão pública almejada para a arquitetura.

No desenho das fachadas, grandes portais marcam o momento limiar de entrada no edifício-praça e consequente saí-

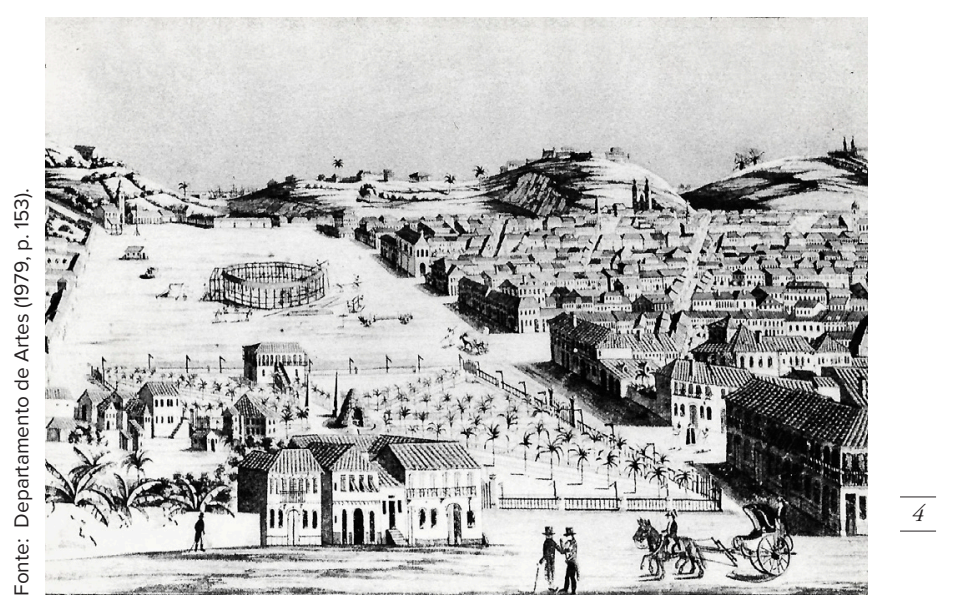

Figura 3. O Campo de Santana do Rio de Janeiro (com a construção de um estádio elítico projetado por Montigny no centro), ilustração feita por Franz Fruhbeck, 1816.

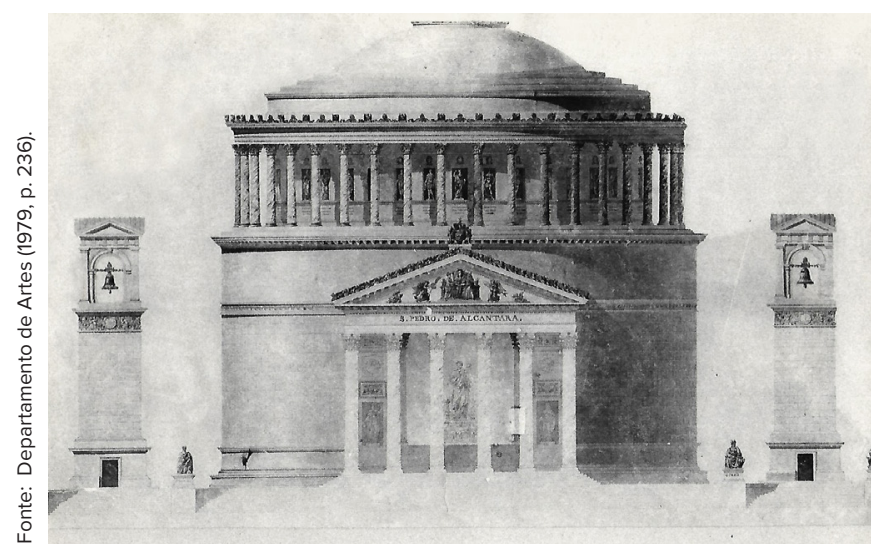

Figura 4. Elevação da Catedral São Pedro de Alcântara, projeto de Montigny, 1827. 
da do Rio de Janeiro. No interior, um espaço generoso e funcionalmente ambíguo, o agitado contexto da cidade é suspenso em uma experiência de intensa percepção temporal. O ambiente anecóico reduz os ruídos urbanos aumentando a capacidade de introversão espacial dos visitantes. O vazio interior é dimensionado e visualmente expandido pelo ritmo constante dos elementos que compõem o espaço - piso, galeria, abóbodas e cúpula - unidos em uma mesma modulação, contribuindo para a criação da monumentalidade pretendida. No mise-en-scène de negociação entre o que a arquitetura pretendia ser e o que de fato era possível construir, Montigny não hesitou em aplicar abundantemente a técnica do faux-marbre em colunas e frisos da galeria que conformam o perímetro da praça interna. No projeto original, junto às paredes de fundo da galeria, ficavam os balcões de atendimento, única indicação visível de sua função. A planta retangular do edifício é subdividida pela disposição espacial em cruz, resolvendo as áreas técnicas nas quatro salas criadas em cada extremidade enquanto libera totalmente uma vasta área central para o público. $\mathrm{O}$ óculo faz clara alusão ao Panteão de Roma, enquanto a planta cruciforme - até então incomum em uma construção laica - lembra a Igreja de Sainte-Geneviève (atual Panteão de Paris), combinação ${ }^{8}$ de tipos espaciais que atribui um caráter sagrado e distinto à arquitetura, mesmo em um edifício ligado estritamente a questões utilitárias da cidade. Usar a Praça do Comércio deveria ser como apropriar um templo público. Tal intenção fica evidente na pintura de Montigny ilustrando a inauguração e o momento de apresentação do edifício ao rei e à sua corte. A imagem exalta a relação de escala entre os visitantes e o interior monumental, representado por uma perspectiva trabalhada no intuito de torná-lo ainda maior do que de fato é.

Assim como recorrente nos protótipos da coleção de Montigny, podemos analisar a indeterminação da arquitetura da Casa França-Brasil pelo modo como o projeto do seu espaço interior, não funcionalmente condicionado, possibilitou diferentes ocupações - mantendo o edifício socialmente relevante durante os últimos dois séculos. Além de inaugurado como Praça de Comércio em 1820, após a independência do Brasil, foi utilizado pela Alfândega por quase um século devido a sua proximidade com a região portuária da cidade; a partir de 1944, serviu de depósito do Banco Ítalo-Germânico e, de 1956 a 1978, abrigou a sede do II Tribunal do Júri. Após um longo período de restauro finalizado em 1990, o edifício foi transformado em centro cultural, status que possibilitou

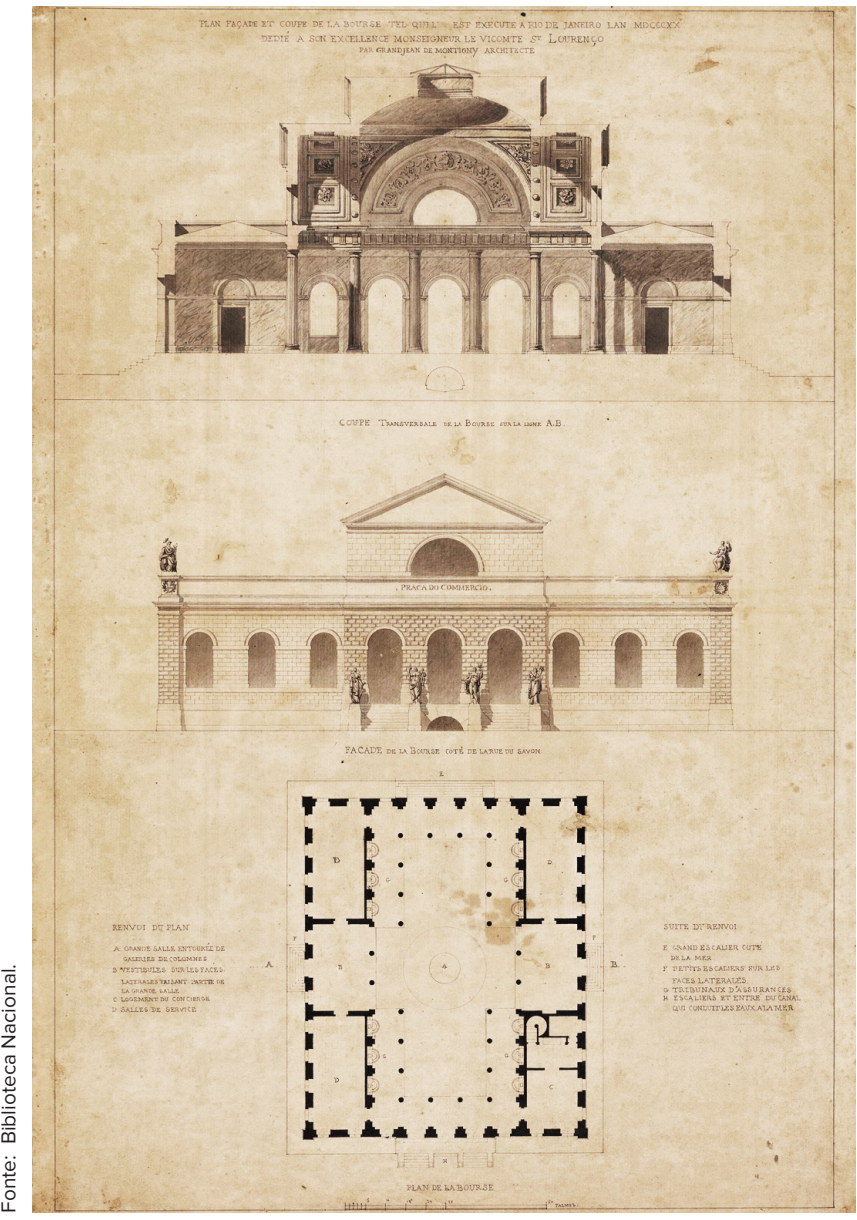

Figura 5. Planta, fachada e corte da Praça do Comércio, conforme projeto original de Grandjean de Montigny, cerca 1819.

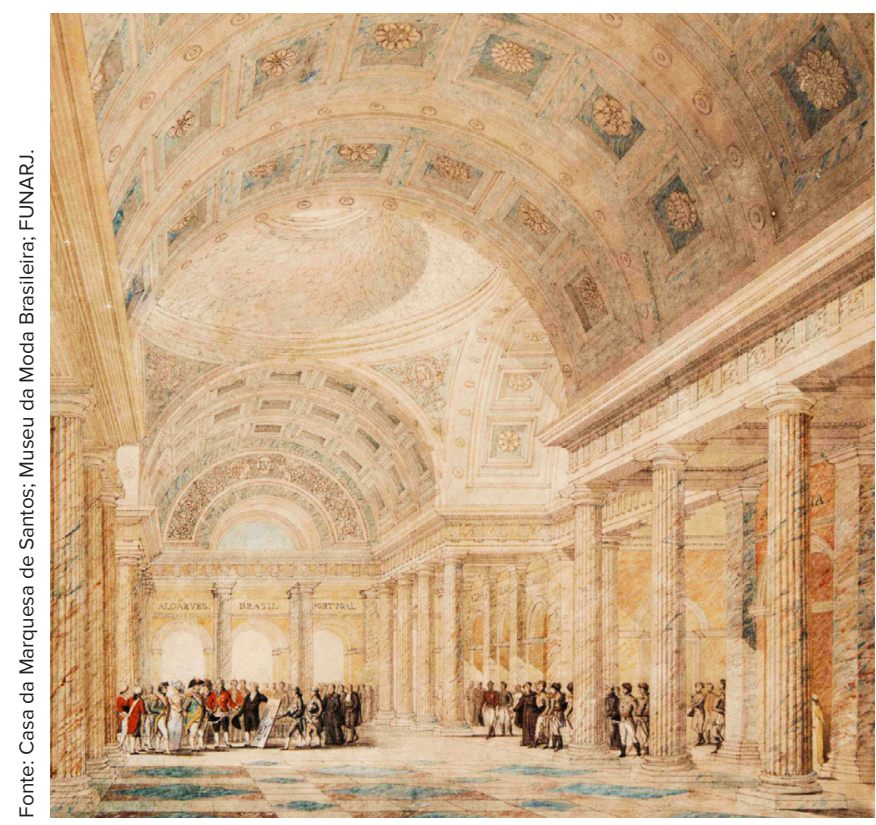

Figura 6. Vista interior da Praça do Comércio no dia de sua inauguração. Grandjean de Montigny, 1820. 
novos tipos de usos e apropriações da generosa "praça-interna" como espaço da cidade.

Desde então, a Casa França-Brasil tem sido palco de diversas exposições e eventos artísticos, feiras e festividades que a aproximaram novamente da sua condição pública original. Por outro lado, são também interessantes os intervalos na agenda cultural nos quais o edifício se apresenta vazio. É quando assume o simples papel de praça coberta de extensão da cidade, onde visitantes experimentam breves pausas de descanso e contemplação, o momento no qual a nobre monumentalidade democrática da arquitetura e de seu espaço interior, ligada ao cotidiano e a coletividade da vida urbana, se manifesta, assim como a premissa principal do projeto.

Em paralelo, a especificidade dessa arquitetura de Montigny, alcançada a partir de suas qualidades formais e espaciais clássicas - exaltadas desde o dia da inauguração ${ }^{9}$ - contribuiu no longue durée para a formação de um entendimento social coletivo sobre sua importância para a cidade enquanto edifício e artefato histórico, em uma possível consumação do que Rossi chamaria de "monumento". ${ }^{10}$ Desse modo, podemos supor que tal especificidade também tenha tido certo grau de influência

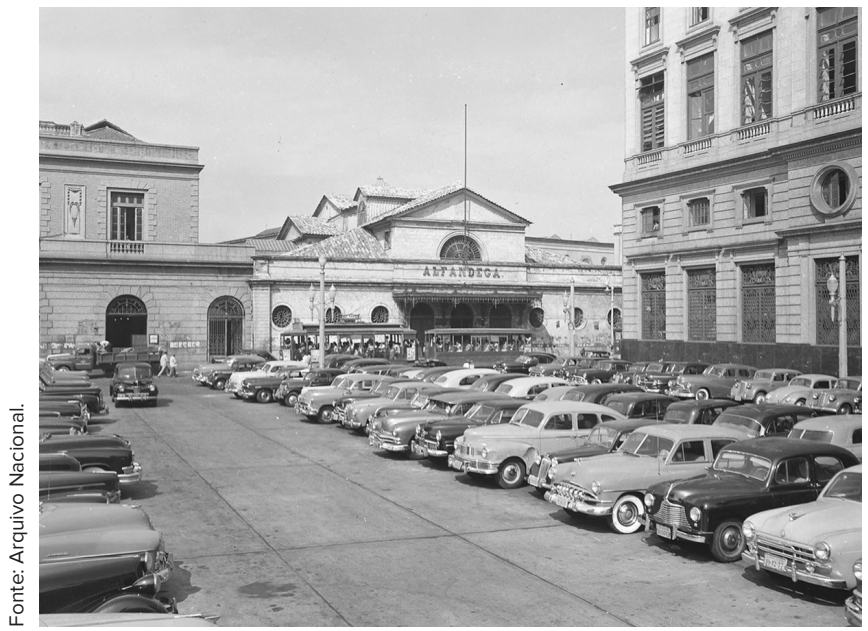

Figura 7. A Casa França-Brasil como Alfândega, 1954.

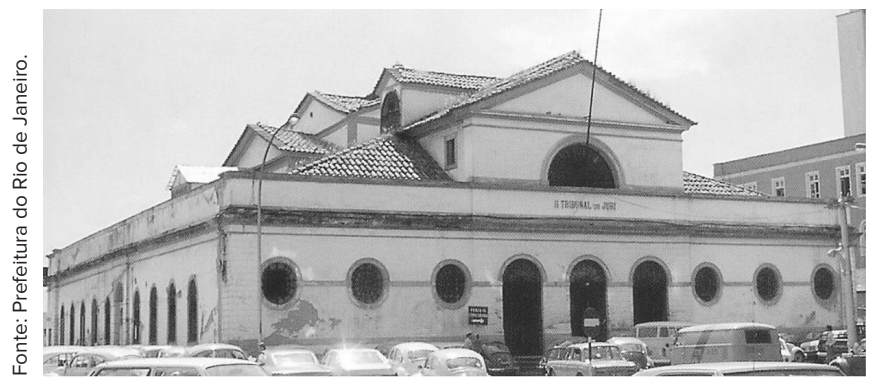

Figura 8. A fachada da Casa França-Brasil como II Tribunal do Júri, 1960. na manutenção da integridade física do edifício. Não somente diante das demandas espaciais derivadas das diferentes ocupações ocorridas, mas também em relação às transformações urbanas que aconteceram no Rio de Janeiro nos últimos séculos. Quando inaugurado, o edifício tinha implantação destacada e interface direta com a orla - a qual foi afastada nos anos seguintes devido ao aterramento da região portuária. Passou por décadas totalmente escondido por sobrados construídos ao seu redor em razão da rápida densificação ocorrida no Centro ao longo do século XIX. Hoje, como Casa França-Brasil, se encontra novamente em destaque na cidade após um processo de grandes intervenções urbanas, iniciado com a abertura da Avenida Presidente Vargas, em 1944, e com a construção e demolição do Elevado da Perimetral entre os anos de 1960-2014.

Em 2021, um ano após celebrar o seu segundo centenário, a Casa França-Brasil continua a representar um protótipo espacial único que nos permite analisar a importância que a teoria de projeto de Grandjean de Montigny pode ter para a prática contemporânea. $O$ valioso entendimento da arquitetura como um saber coletivo e acumulado demonstra não só a viabilidade, como também a necessidade de aproximação com um repertório de referências projetuais de um passado que, à primeira vista, parece-nos longe demais para ser relevante.

Salvatore Settis (2006), no livro The Future of the "Classical", define o Clássico como algo que não pode ter seu tempo de origem definido, tal qual uma qualidade encontrada de modo recorrente através das eras - inteligível ainda que em diferentes formas, materialidades e contextos. Enquanto representante e agente responsável pela continuidade dessa herança cultural, o que parecia elementar para Montigny não era exatamente o uso de ordens e ornamentos, mas um caráter construtivo específico que definisse a qualidade clássica e atemporal de uma arquitetura. Por outro lado, a precisa indeterminação espacial foi o fator que possibilitou a esta arquitetura se manter valiosa para a cidade ao longo dos anos em especial por intermédio do generoso interior capaz ainda hoje de abrigar usos diversos para além daquele que serviu de álibi para sua construção.

A arquitetura nasceu da necessidade, agora é autônoma; na sua forma mais sublime, cria espaços de museu que são utilizados por técnicos de modo a serem transformados e adaptados para as múltiplas funções às quais devem servir. (ROSSI, [1968] 1977, p. 210, tradução do autor)

Revista online do Departamento de Arquitetura e Urbanismo da Pontifícia Universidade Católica do Rio de Janeiro - PUC-Rio, Brasil Ano 8 - No 9 - ISSN 2446-7340 
Acredito que a arquitetura da Casa França-Brasil possa ser descrita a partir de suas duas intenções principais, aparentemente opostas, porém complementares: a concepção de uma arquitetura distinta baseada em certas noções universais de qualidade formal/espacial e na analogia com um campo referencial teórico que comunica sua raison d'être; e a utilização da monumentalidade constituída para delimitar um vazio urbano com o objetivo de mantê-lo livre e repleto de possibilidades, em um modo simultaneamente específico e indeterminado. Uma verdadeira arquitetura da cidade.

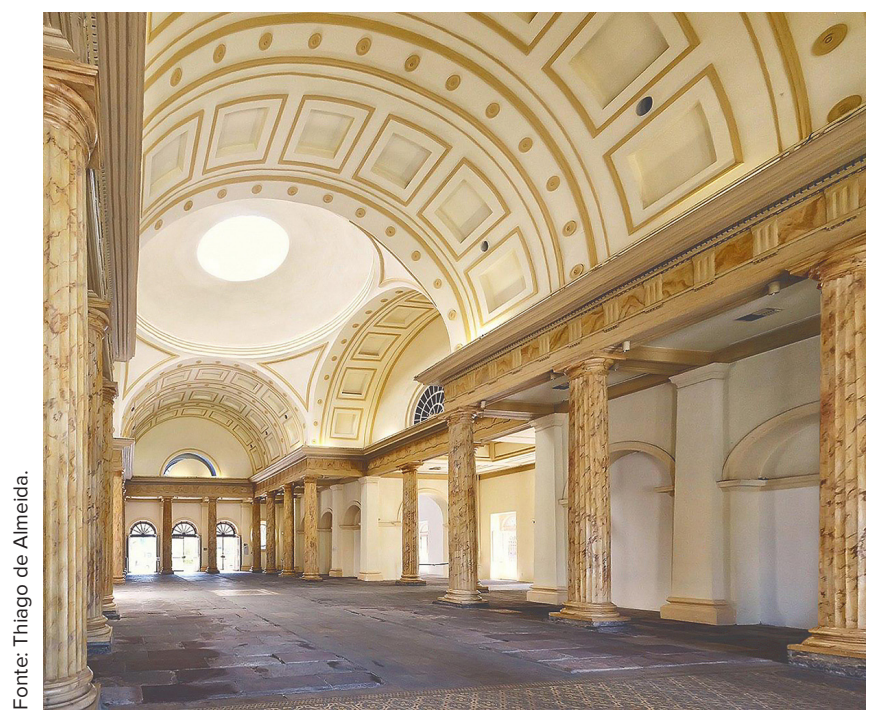

Figura 9. Interior da Casa França-Brasil, 2020.

\section{Notas de fim:}

1. Entre outros belos pensamentos desenvolvidos no texto, Rossi afirma: "Essa ideia pode ser encontrada nos escritos de Adolf Loos, onde ele declara que a arquitetura pode somente ser descrita e não desenhada. Este tipo de formulação lógica permite uma descrição característica da boa arquitetura. O Panteão pode ser descrito, os edifícios da Secessão (austríaca) não. (...) A arquitetura deve ser trazida de volta a si mesma" (ROSSI, [1968] 1977, p. 206, tradução do autor).

2. Rossi alertava para a incoerência de uma nova arquitetura se basear somente em seu contexto urbano imediato, pois ao existir, ela iria inevitavelmente alterá-lo. O autor afirma que "devemos notar que seria tolice pensar que o problema da arquitetura pode ser resolvido apenas do ponto de vista composicional, ou revelado, por meio de um contexto ou de uma suposta extensão dos parâmetros de um contexto. Essas soluções não fazem sentido, porque o contexto é específico precisamente no que se refere à arquitetura" (ROSSI, [1966] 1984, p. 127, tradução do autor).

3. A Missão Artística Francesa foi um grupo de artistas franceses que vieram ao Brasil no início do século XIX, a convite de Portugal, com o objetivo de estabelecer o ensino e a promoção das artes plásticas na cidade colonial que viria a se tornar a nova capital do reino português.

4. Entre as muitas referências ao conceito de autonomia feitas por Rossi no livro Arquitetura da Cidade, destaco a seguinte passagem: "Estou, portanto, disposto a acreditar que o momento principal de um artefato arquitetônico está na sua formação técnica e artística, ou seja, nos princípios autônomos segundo os quais é fundado e transmitido. Em termos mais gerais, está na solução concreta que cada arquiteto dá ao seu encontro com a realidade, solução verificável precisamente porque se apoia em certas técnicas” (ROSSI, [1966] 1984, p. 127, tradução do autor).

5. O uso de tipos era técnica também comum entre os arquitetos neo-clássicos. Foi recuperada por Rossi pelos estudos de Quatremère de Quincy, arqueólogo francês, contemporâneo a Montigny, autor da teoria sobre tipos que serviu de base para a arquitetura neoclássica.

6. Longue durée (longa duração, em português) é um conceito histórico criado pelo historiador francês Fernand Braudel no estudo da história através da análise de fenômenos extremamente longos como a evolução das paisagens e a história da humanidade.

7. Outro importante edifício de Montigny ainda existente é a sua casa na Gávea (hoje Solar Grandjean de Montigny, localizado no campus da Pontifícia Universidade Católica do Rio de Janeiro), projetada por ele no mesmo período da construção da Praça do Comércio (1820).

8. Essa combinação espacial também é encontrada em outros projetos de Montigny feitos à época da França Revolucionária de Napoleão.

9. Segundo a opinião do historiador Ferdinand Denis, a Praça do Comércio era "certamente um dos mais notáveis edifícios do Rio de Janeiro” (RIOS FILHO, 1941, p. 243). O sucesso do projeto rendeu a Montigny, no dia da inauguração do edifício, a condecoração da Ordem de Cristo diretamente das mãos do rei D. João VI.

10. Rossi via na "permanência urbana" de certos edifícios a possibilidade de interpretá-los como monumentos. "Estou inclinado a acreditar que a persistência de um artefato urbano muitas vezes faz com que ele seja identificado como monumento, e que um monumento persiste na cidade tanto simbólica quanto fisicamente. A [...] permanência de um monumento resulta da sua capacidade de constituir a cidade, da sua história e arte, de sua existência e memória" (ROSSI, [1966] 1984, p. 6o, tradução do autor). 


\section{Referências Bibliográficas:}

COSTA, Lucio. Lucio Costa: registros de uma vivência. São Paulo: Empresa das Artes, 1995 .

DEPARTAMENTO DE ARTES, Pontifícia Universidade Católica do Rio de Janeiro (Org.). Uma cidade em questão: Grandjean de Montigny e o Rio de Janeiro. Rio de Janeiro: PUC-Rio, 1979. Catálogo de exposição. Disponível em: http://objdigital.bn.br/objdigital2/acervo_digital /div_iconografia/icon1393187/icon1393187.pdf. Acesso em: 02, nov. 2021.

MONTIGNY, Grandjean Auguste; FAMIN, Auguste. Architecture Toscane: Palais, Maisons et Autres Édifices de la Toscane, mesurés et dessinés. Paris: P. Didot, 1815.

RIOS FILHO, Adolfo Morales de los. Grandjean de Montigny e a evolução da arte brasileira. Rio de Janeiro: A Noite, 1941.

ROSSI, Aldo. The Architecture of the City. (1966). Cambridge: MIT Press, 1984 .

. Arquitectura para los museos. (1968). In: Para una arquitectura de tendenza: Escritos 1956-1972. Barcelona: Gili, 1977.

SETTIS, Salvatore. The Future of the Classical. Hoboken: Wiley, 2006.

TELLES, Angela. Grandjean de Montigny: Da Arquitetura Revolucionária à Civilização nos Trópicos. Rio de Janeiro: Arquivo Nacional, 2008. 